\title{
El papel del estado en la formación de los apellidos: la Navarra francesa y la Navarra española
}

\section{The role of the state in the formation of surnames: the French Navarre and the Spanish Navarre}

\author{
Ana Zabalza-Seguín \\ Departamento de Historia, $\mathrm{H}^{\mathrm{a}}$ del Arte y Geografía. Universidad de Navarra \\ https://orcid.org/0000-0003-3312-597X \\ azabalza@unav.es
}

\section{Resumen}

Este trabajo aborda el estudio del sistema onomástico durante la Edad Moderna en el reino de Navarra tras su división en dos partes, una de las cuales se integró en España y otra en Francia. Se trata de probar la hipótesis de que, durante el Antiguo Régimen, el papel del estado ha sido más intenso en la Navarra española que en la francesa. Para ello, se ha analizado una extensa ejecutoria (1755) obtenida por un hidalgo oriundo de la parte francesa pero avecindado en la española; de ella se extrae tanto la genealogía del solicitante como información sobre numerosos testigos de uno y otro lado de la frontera. El análisis de los modos en que estos individuos son identificados ha permitido probar la hipótesis de partida: el sistema onomástico tradicional, que vinculaba la identidad personal al solar más que a la filiación un apellido o al lugar de vecindad, se mantenía a mediados del XVIII al norte de los Pirineos, mientras que en la Monarquía Hispánica se advierten rasgos de mayor modernidad, junto con más peso del papel masculino.

Palabras clave: Reino de Navarra; Origen de los apellidos; Onomástica; Antroponimia; Loigorri.

\begin{abstract}
The focus of this paper is the analysis of the onomastic system in the kingdom of Navarre during the Early Modern Age, after its division into two parts, one of which was integrated in Spain and another in France. The aim is to test the hypothesis that, during the Ancien Régime, the role of the State has been more intense in Spanish Navarre than in French Basse-Navarre. To do this, an extensive Ejecutoria (1755) obtained by a hidalgo native from the French part but settled in the Spanish one has been analyzed; from it, both the genealogy of the applicant and information about numerous witnesses on both sides of the border are extracted. The analysis of the ways in which these individuals are identified has allowed us to test the hypothesis: the traditional onomastic system, which linked the identity to the household rather than to a filiation or to the place of neighborhood or place of neighborhood, was maintained in the mid-18th century north of Pyrenees, while in the Hispanic Monarchy there are features of greater modernity, along with more weight in the male role.
\end{abstract}

Keywords: Kingdom of Navarra; Origin of family names; Onomastics; Anthroponymy; Loigorri. 
Onomástica Desde América Latina, n. 2, v. 1, julho - dezembro, 2020, p. 17- 44. ISSN 2675-2719 https://doi.org/10.48075/odal.v1i2.25491

\section{Introducción: la construcción del estado moderno y la escala local ${ }^{1}$}

"There is no State-making without State-naming" (SCOTT, TEHRANIAN y MATHIAS, 2002: 4). La gigantesca tarea de articular un estado requiere la identificación segura de los individuos que viven en él, y tal empresa, a comienzos de la Edad Moderna, estaba por hacer. Un gobierno eficaz precisa centralización, integración, identificación. El descenso a la escala local en cualquier región europea durante estos siglos permite comprobar que se trataba de un mundo opaco para el forastero, en particular para los oficiales del naciente estado, quienes se encontraban ante códigos imposibles de descifrar. Cada sociedad, utilizando su lengua propia, ha calificado y designado la realidad circundante, tanto lo que se refiere al entorno material como a las relaciones humanas, de una forma plenamente eficaz y con frecuencia con una notable economía de medios, reflejando su manera de ver y de relacionarse con la realidad. Pero para el observador externo, desconocedor de esa visión y con frecuencia también de la lengua vernácula, los nombres de los lugares y de las personas resultan vacíos de significado y las pautas de asignación sencillamente caóticas. Como parte de un proyecto uniformador mucho más amplio, una de las tareas del incipiente estado va a consistir en establecer sistemas estandarizados de nombres personales estables, conforme a sus propias taxonomías, de tal manera que un individuo pueda ser eficazmente identificado a cualquier efecto con términos que indiquen de modo claro y permanente tanto su sexo como su filiación (SCOTT, TEHRANIAN y MATHIAS, 2002: 6).

En este texto me propongo explorar algunos aspectos de este proceso - en particular la fijación del apellido - en un pequeño reino europeo, Navarra, que por una serie de decisiones tomadas entre 1512 y 1620 se dividió en dos partes, una de las cuales — la mayor - se integró en la Monarquía Hispánica, mientras que la menor engrosó el reino de

\footnotetext{
${ }^{1}$ Este trabajo se inscribe en el proyecto de investigación DER2016-79292-R Instituciones y personas que actuaron como puente de enlace entre Navarra y la Monarquía Hispánica, financiado por el Ministerio de Economía, Industria y Competitividad.
} 
Onomástica Desde América Latina, n. 2, v. 1, julho - dezembro, 2020, p. 17- 44. ISSN 2675-2719 https://doi.org/10.48075/odal.v1i2.25491

Francia. Situadas en posiciones periféricas de ambos territorios, con una población hablante de una lengua minoritaria no romance, la vasca, sin parentesco con las de las regiones circundantes, se trata de ver cómo los vecinos de una y otra Navarra vivieron el proceso de convertirlos en sujetos legibles (SCOTT, TEHRANIAN y MATHIAS, 2002: 4, 37) para sus nuevos soberanos. Para ello, me he servido de un extenso manuscrito de 1756 que recoge la ejecutoria obtenida por un hidalgo el año anterior, y que contiene abundante información sobre navarros de uno y otro lado de la frontera, cuando había transcurrido más de un siglo desde la definitiva integración del apéndice septentrional en Francia, y más de dos desde la incorporación del meridional a la Monarquía Hispánica. El hidalgo en cuestión era don Gracián de Echapare y Loigorri, oriundo por vía paterna y materna de la Navarra francesa, pero asentado en la parte española, quien junto con su esposa solicitó que se les reconociera el derecho a utilizar los escudos de armas de sus casas nativas ${ }^{2}$. La investigación a que dio lugar requirió el testimonio de personas de ambos lados de la frontera, lo que proporciona una instantánea del sistema onomástico en uso en territorios periféricos tanto de Francia como de la Monarquía Hispánica, y permite analizar los resultados producidos por estos dos agentes tras actuar sobre los vecinos del antiguo reino de Navarra. La hipótesis de que parto es que, en el campo de los apellidos, la castellanización de la Navarra española fue más intensa, a mediados del XVIII, que el impacto sufrido en Baja Navarra por la acción de las autoridades bearnesas o francesas.

\footnotetext{
${ }^{2}$ Ejecutoria y certificación del escudo de armas de los apellidos Echapare, Loigorri, Virto y Casado, a petición de Gracián de Echapare y Loigorri y su mujer Josefa Virto y Casado, vecinos de Cintruénigo (Navarra), 1756, 584 p. Puede consultarse en la Biblioteca Digital de la Fundación Sancho el Sabio, http://hdl.handle.net/10357/1803. La numeración de las páginas, que no figura en el manuscrito, es de la autora de este texto.

Es preciso señalar que el manuscrito que he manejado es una copia, realizada por un único amanuense, de la muy abundante documentación generada por la probanza del derecho solicitado, obra de muchas manos. Por tanto, debe contemplarse la posibilidad de que el manuscrito contenga erratas o variaciones deliberadamente introducidas por quien sin duda trabajó al servicio del solicitante.
} 


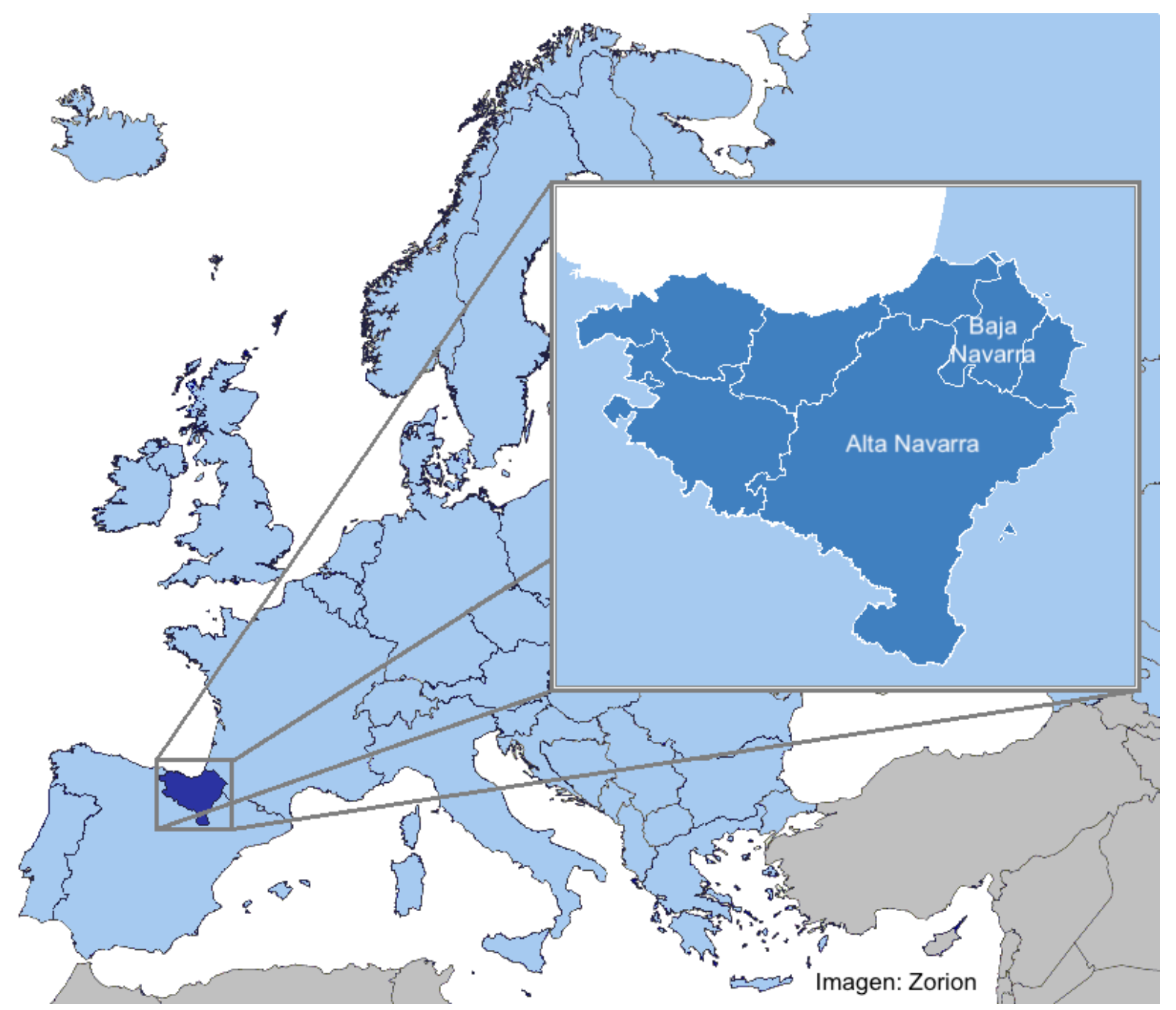

Mapa $n^{\circ}$ 1. Alta y Baja Navarra en Europa. Autor: Zorion.

\section{https://upload.wikimedia.org/wikipedia/commons/e/eb/Euskal_Herria_Europa.png}

Antes de continuar conviene realizar alguna precisión terminológica. Hasta 1527, el reino de Navarra comprendía territorios tanto al norte como al sur de los Pirineos. El apéndice septentrional - $10 \%$ del total — queda fuera de la Península Ibérica, y debido a su menor altitud sobre el nivel del mar recibe el nombre de Baja Navarra; también es conocido como Ultrapuertos. Otra denominación frecuentemente utilizada es la de Tierra de vascos, o simplemente Vascos, a causa de que la lengua vasca era un factor que distinguía a los bajonavarros de sus inmediatos vecinos, hablantes de dialectos del occitano. Desde 1620 se le puede calificar también de Navarra francesa. En cambio, Alta Navarra - la parte más extensa- es el territorio peninsular, y constituye la Navarra española. En esta, la población 
Onomástica Desde América Latina, n. 2, v. 1, julho - dezembro, 2020, p. 17- 44. ISSN 2675-2719 https://doi.org/10.48075/odal.v1i2.25491

de la mitad más septentrional era de habla mayoritariamente vasca, mientras que al sur dominaba el romance, si bien en uno y otro ámbito se daban excepciones: por ejemplo, en los núcleos urbanos del área vascongada vivían personas hablantes del castellano (MONTEANO, 2017: 153-172).

El estudio de sociedades del pasado a través de las fuentes escritas que han llegado hasta nosotros presenta, entre otras, la dificultad de corregir el sesgo de género, un aspecto que, al abordar la onomástica personal, su uso y transmisión, reviste importancia. Los nombres vernáculos constituyen breves descripciones que reflejan la vinculación de un individuo con el espacio físico y social; en este sentido la perspectiva que adopta el hablante es un factor esencial. El manuscrito aquí analizado ofrece el punto de vista masculino - los 36 testigos que declararon fueron hombres,$-{ }^{3}$ pero no puede asumirse como punto de vista global. Por mencionar solo un ejemplo, hace ya cuarenta años que Rogers, desde el campo de la etnología, puso de relieve en su estudio sobre una población campesina de Lorena en la segunda mitad del siglo XX que todavía en esa fecha espacios y tareas obedecían rigurosamente a la segregación por sexos que regía la vida local; hombres y mujeres se movían en distintos ámbitos y realizaban diferentes trabajos; unos y otras se relacionaban con personas de su mismo sexo y lo hacían de manera también diversa (ROGERS, 1979). Si esto pudo afirmarse de una comunidad en la Edad Contemporánea, más aún cabría aplicarlo al pasado. Los registros escritos responden al punto de vista masculino, tanto en el nivel normativo como en la práctica notarial: el escribano es siempre un hombre y en la mayoría de los casos quienes acuden a su despacho también. Esta circunstancia debe tenerse en cuenta porque la otra mitad de la población cuenta con una experiencia vital y un modo de identificar a las personas propio: no puede tomarse lo masculino como único criterio normativo. La tarea

\footnotetext{
${ }^{3}$ En este trabajo me centro exclusivamente en los testigos que declararon por parte de don Gracián de Loigorri, sin atender a los que lo hicieron por su esposa pues éstos solo remiten a la Alta Navarra.
} 
Onomástica Desde América Latina, n. 2, v. 1, julho - dezembro, 2020, p. 17- 44. ISSN 2675-2719 https://doi.org/10.48075/odal.v1i2.25491

de descartar ese sesgo es tan necesaria como compleja. En el caso que se presenta en este trabajo, el análisis de la onomástica permite atisbar que el papel de la mujer tenía un peso mayor de lo que la propia documentación literalmente transmite, y conocerlo contribuye a explicar algunas aparentes anomalías.

\section{Navarra: un reino dividido}

Las circunstancias que acompañaron y siguieron la división del reino pueden ayudar a comprender los procesos que aquí se analizan. El reino de Navarra sufrió en 1512 una conquista militar por parte de Fernando el Católico, rey de Aragón y regente de Castilla, quien en 1515 incorporó este territorio a la corona de Castilla. Si bien el monarca conquistó toda Navarra, pocos años después, hacia 1527, su nieto Carlos I optó por abandonar el apéndice septentrional del territorio situado al norte de los Pirineos, seguramente por la dificultad que planteaba su defensa, pues, además de ser pobre y estar superpoblado (HERREROS, 1996: 226-228), como hemos visto quedaba fuera del espacio peninsular. Se trataba de configurar una línea fronteriza segura, habida cuenta de que la rivalidad entre Francia y España hacía de Navarra un punto de fricción que, de una manera u otra, se mantendría candente durante toda la Edad Moderna. La Monarquía Hispánica había conservado la parte con diferencia más extensa y rica del viejo reino medieval, e hizo de Pamplona, su ciudad principal, un baluarte militar: uno más de los que jalonaban la barrera pirenaica a ambos lados de la frontera entre los dos países. ${ }^{4}$

Al conflicto político vino a sumarse el religioso, complicando todavía más tanto las relaciones de los dos países como la situación de Navarra. Tras la rápida conquista de 1512, los Albret, reyes legítimos de Navarra, se vieron obligados a buscar refugio en los dominios que conservaban al sur de la actual Francia — ante todo, el Bearne-, de los que el pequeño

\footnotetext{
${ }^{4}$ Baja Navarra contaba únicamente con una población de carácter urbano, San Juan de Pie de Puerto, villa con asiento en las Cortes de Navarra hasta la fractura del reino.
} 
Onomástica Desde América Latina, n. 2, v. 1, julho - dezembro, 2020, p. 17- 44. ISSN 2675-2719 https://doi.org/10.48075/odal.v1i2.25491

enclave de Baja Navarra era el único que les permitía titularse reyes. Los intentos de recuperar el reino perdido por parte de los Albret fracasaron. En 1560 la reina Juana, nieta de los últimos monarcas, se convirtió al calvinismo e inició una política hostil a los católicos. El secular movimiento migratorio del norte al sur del antiguo reino, que transfería excedentes demográficos a las tierras más ricas y menos densamente pobladas de la Navarra Media y Ribera del Ebro, probablemente se intensificó. Resulta difícil cuantificar este flujo, pues los bajonavarros, más allá de los avatares políticos o militares, no se diferenciaban de los altonavarros — sobre todo de los de comarcas próximas a la frontera- en dos rasgos fundamentales: la lengua y, por encima de todo, la religión, lo que facilitaba su pronta asimilación. Las ricas fuentes conservadas en el Archivo Real y General de Navarra — de modo particular, los procesos judiciales de la Edad Moderna - dan cuenta de la numerosa presencia de inmigrantes procedentes de los valles bajonavarros, hombres y mujeres, llegados siendo casi niños para trabajar como pastores, mozos de labranza, criados o aprendices de distintos oficios. Es precisamente la onomástica la que nos permite descubrir su origen, pues con frecuencia no tienen más apellido que el nombre de su lugar natal. ${ }^{5} \mathrm{Su}$ asimilación se producía sin conflictos; de las fuentes se deduce que no formaron grupo cerrado ni se asentaron de manera preferente en determinadas poblaciones, sino que se diseminaron por toda la Alta Navarra, buscando en particular las localidades donde, por la abundancia en tierra y ganado, serían mejor recibidos: es decir, en las cuencas pre-pirenaicas y en el sur, en el valle del Ebro. Su aspiración, lograda en un buen número de casos, era la plena integración en la

\footnotetext{
${ }^{5}$ Todavía hoy en Navarra son frecuentes los apellidos toponímicos que remiten a estas poblaciones del norte de los Pirineos: concretamente, de los 50 más frecuentes entre los nacidos en la actual Comunidad Foral, al menos tres son con seguridad de esa procedencia: Sola ( $\mathrm{n}^{\mathrm{o}}$ 20; no es bajonavarro sino suletino), Armendáriz $\left(\mathrm{n}^{\circ} 29\right)$ y Osés ( $\left.\mathrm{n}^{\circ} 35\right)$. En el caso de apellidos que son originalmente oicónimos, como Echeverría $\left(\mathrm{n}^{\circ} 12\right)$, Iriarte $\left(\mathrm{n}^{\circ} 19\right)$, Elizalde $\left(\mathrm{n}^{\mathrm{o}} 37\right)$, Irigoyen $\left(\mathrm{n}^{\circ} 41\right)$ e Iribarren $\left(\mathrm{n}^{\circ} 43\right)$, no es posible determinar su procedencia pues es múltiple y habría que examinar caso por caso; otro tanto sucede con los que responden a localidades homónimas de ambas Navarras, como Huarte ( $\left.\mathrm{n}^{\mathbf{o}} 31\right)$ y Zabalza (n 36): www.ine.es (consultado 07/10/2019).
} 
Onomástica Desde América Latina, n. 2, v. 1, julho - dezembro, 2020, p. 17- 44. ISSN 2675-2719 https://doi.org/10.48075/odal.v1i2.25491

Navarra peninsular, obtenida de manera informal, generalmente por matrimonio con el dueño o dueña de una casa vecinal: una meta que probablemente alentó su dispersión.

El trasvase de contingentes demográficos de la Baja a la Alta Navarra tenía antiguas raíces. La Tierra de vascos constituyó desde la Edad Media un vivero de emigrantes, muchos de los cuales se enrolaron como mercenarios (BRUNET, 2014: 81-88). Mientras fue reino independiente, hasta 1512, la corte del rey, establecida con preferencia en el palacio de Olite, donde Navarra se abre al valle del Ebro, contó con la presencia de un elevado número de cortesanos bajonavarros, muchos de ellos miembros de la baja nobleza dueña de los palacios o salas que salpicaban aquel territorio. Monteano ha estimado que los nobles bajonavarros establecidos en la corte eran proporcionalmente el triple de lo que correspondería por la extensión de su territorio, que como se ha dicho constituía solamente una décima parte del antiguo reino de Navarra (Monteano, 2015: 164-165). Resulta indudable que estos nobles buscaron igualmente el establecimiento definitivo en la Navarra peninsular, por lo que como pago de su servicio al monarca aspiraron a ser recompensados con donaciones de tierras: y no se vieron defraudados.

Que la frontera política se convirtiera también, desde 1560, en frontera religiosa (BRUNET, 2017: 164-165) marcó sin duda un punto de inflexión en ese permanente flujo migratorio. Pese a que en general los bajonavarros ofrecieron notable resistencia al calvinismo (FLORISTÁN, 2006: 127), sí hubo conversiones en familias destacadas. Algunas de las iglesias de los lugares cuyo señor abrazó la Reforma fueron cerradas y el culto católico, prohibido (RIEZU, 1985: 542), por lo que puede deducirse que los vecinos que sufrieran esa actitud hostil se sintieran impulsados a abandonar sus casas, intensificando así la llegada de emigrantes a la Navarra peninsular, si bien, a falta de estudios sobre la materia que abarquen 
Onomástica Desde América Latina, n. 2, v. 1, julho - dezembro, 2020, p. 17- 44. ISSN 2675-2719 https://doi.org/10.48075/odal.v1i2.25491

la totalidad del territorio, hemos de conformarnos con suponerlo. ${ }^{6}$ Por esas mismas fechas, Felipe II, inquieto por el hecho de que una parte de sus súbditos navarros dependiera de obispos franceses - los valles septentrionales escapaban a la jurisdicción del obispo de Pamplona (GOÑI GAZTAMBIDE, 1985: 214-222) — impulsó su incorporación a esta en 1566, apartándolos de la obediencia de los obispos de Dax y Bayona y profundizando así en la división.

La ruptura entre las dos Navarras se ahondó aún más a raíz de la ley promulgada por las Cortes de Navarra, reunidas en la ciudad de Tudela en 1583 (VÁZQUEZ DE PRADA, 1993: 329): en virtud de ella, los de Ultrapuertos perdían la naturaleza de navarros de la que venían disfrutando hasta entonces, de manera que pasaban a ser considerados extranjeros y en lo sucesivo no podrían disfrutar de oficios ni beneficios, civiles ni eclesiásticos. Esta medida afectaba tanto a los recién llegados como a los que tenían en su horizonte vital la emigración y veían así truncada la vía de salida desde sus pobres valles. No hay que olvidar que la incorporación del reino de Navarra a Castilla en 1515 había coincidido prácticamente con el inicio de los viajes de exploración y conquista de las tierras descubiertas en América; los navarros habían pasado a ser además castellanos, y como tales, habilitados para la empresa atlántica. Dejar de ser navarro significaba dejar de ser castellano, lo que cortaba cualquier expectativa de salida tanto hacia Navarra y Castilla como hacia Indias. Retenidos en un pequeño territorio incapaz de sostener su población, no quedaban más opciones que Francia, en aquel momento envuelta en las guerras de religión (1562-1598), y donde las barreras religiosas, lingüísticas y culturales no permitían una asimilación tan fluida como la que habían experimentado en la Navarra peninsular. El asesinato, en 1610, de Enrique III de Navarra y IV de Francia precipitó los acontecimientos, al desaparecer el monarca que

\footnotetext{
${ }^{6}$ No deja de resultar significativo que en el principal trabajo de síntesis sobre la inmigración francesa en España durante la Edad Moderna se dedique un apartado prácticamente a todas las regiones, incluidos los archipiélagos, pero no se haga lo propio con Navarra, que por su situación geográfica hubo de ser una de las principales receptoras (SALAS AUSÉNS, 2009)..
} 
Onomástica Desde América Latina, n. 2, v. 1, julho - dezembro, 2020, p. 17- 44. ISSN 2675-2719 https://doi.org/10.48075/odal.v1i2.25491

personificaba la vinculación de Baja Navarra con Francia. Su sucesor, Luis XIII, no tardó en promulgar (1611) unos fueros que modificaban sustancialmente el contenido de los tradicionales (FLORISTÁN, 2007: 210) y anticipaban lo que aconteció poco después: en 1620, el monarca incorporó este pequeño territorio a la corona francesa, en una decisión que culminó la separación entre las dos partes de Navarra. Durante un siglo los bajonavarros habían sido de manera simultánea súbditos de dos reinos (BRUNET, 2014: 68).

Pese a todo, los vínculos que enlazaban las dos partes del antiguo reino — fundados en relaciones de parentesco, amistad o negocio- eran tan estrechos que no se interrumpieron. Los bajonavarros ya asentados en la Península no olvidaban sus solares originarios ni a sus parientes, entre los que menudeaban las visitas. El pasado compartido, junto con la complementariedad de sus recursos, habían generado costumbres que se mantuvieron, como la participación de los bajonavarros en las ferias de Roncesvalles, cuya colegiata era titular de no pocas propiedades allende los Pirineos, y Burguete, puesto fronterizo cuya tabla experimentó un notable incremento en la circulación de mercancías a lo largo del XVI (FLORISTÁN, 2014: 119), así como la feria de San Fermín de Pamplona, a la que concurrían para vender ganado. ${ }^{7}$ En esos desplazamientos, que podían durar varios días, se alojaban en casas de vecinos y parientes, circunstancia que aprovechaban para transmitir noticias y recados, así como para procurarse artículos difíciles de conseguir en Baja Navarra. ${ }^{8}$

\section{Vínculos humanos que unen las dos vertientes: el estudio de caso}

El ejemplo elegido para este trabajo tiene como protagonistas a una serie de casas que vivieron los procesos antes explicados. En estas casas - en el mundo pirenaico es el verdadero sujeto social $-9{ }^{9}$ se perciben con claridad una serie de rasgos y tendencias

\footnotetext{
${ }^{7}$ Ejecutoria y certificación..., fo 302: declaración del testigo Lorenzo de Mendi; f e 311-312: declaración del testigo Gracián de Urruti, entre otros.

${ }^{8}$ Ejecutoria y certificación..., f $\mathrm{f}^{\mathrm{0}}$ 312: declaración del testigo Gracián de Urruti.

${ }^{9}$ La bibliografía sobre esta materia es inmensa. Una actualización (Chacón, 2011); una explicación aplicada a Navarra (YABEN, 1916).
} 
Onomástica Desde América Latina, n. 2, v. 1, julho - dezembro, 2020, p. 17- 44. ISSN 2675-2719 https://doi.org/10.48075/odal.v1i2.25491

características de la región: en particular, la transmisión de todo el patrimonio, en cada generación, a un único heredero, que en los Pirineos occidentales es elegido libremente por los padres y puede ser tanto un hijo como una hija; en consecuencia, los restantes son desheredados y, tras recibir la dote y legítima de su casa nativa, en ocasiones complementada con el fruto de su trabajo personal, contraen matrimonio con el heredero o heredera de otra casa. Si por algún motivo esta salida no puede efectuarse, los hermanos tienen derecho a permanecer toda su vida en la casa nativa, trabajando al servicio de esta, pero manteniéndose solteros. Se trata de un sistema común en las regiones montañosas de Europa durante el Antiguo Régimen, que incluso se prolongó terminado este, y que como veremos tiene importancia a la hora de fijar la onomástica: en una sociedad en la que la relación del ser humano con el solar y la tierra revisten importancia fundamental, el mismo nombre con el que una persona es conocida deriva precisamente de su relación con una y otra: el solar originario, la casa. Esto resulta patente en un territorio como Baja Navarra, en el que los hijos "expulsados" de la casa por un sistema que busca asegurar el equilibrio entre la población y los recursos, garantizando que en cada generación haya el mismo número de unidades familiares, van a emigrar al sur en busca de oportunidades, y no pocas veces serán conocidos por el nombre de su casa o lugar natal (ZABALZA, 2018: 134-142).

El caso que me propongo analizar habla de los frecuentes desplazamientos de población con motivo de matrimonio, así como del peso del papel de la mujer, quien da estabilidad a la casa. Trata sobre casas de uno y otro lado de la frontera que, pese a compartir un mismo modelo de estructura familiar, presentan a mediados del XVIII ciertos matices diferenciadores. Parto, como ya se ha indicado, de la documentación generada por una familia enriquecida que, en 1755, deseó obtener reconocimiento de ciertos derechos, tras haberse avecindado en una población donde su origen y calidad no eran conocidos. En las dos ramas de origen bajonavarro se daba la circunstancia de que descendían de segundones de las dos 
Onomástica Desde América Latina, n. 2, v. 1, julho - dezembro, 2020, p. 17- 44. ISSN 2675-2719 https://doi.org/10.48075/odal.v1i2.25491

casas cuya descendencia trataban de probar. La reconstrucción genealógica en orden a dejar establecidos sus derechos arranca precisamente de los años que siguieron a la ley de Cortes que privaba a los de Ultrapuertos de su naturaleza de navarros, y permite comprobar las aspiraciones de una pequeña nobleza relativamente abundante en Baja Navarra. 
Onomástica Desde América Latina, n. 2, v. 1, julho - dezembro, 2020, p. 17- 44. ISSN 2675-2719 https://doi.org/10.48075/odal.v1i2.25491

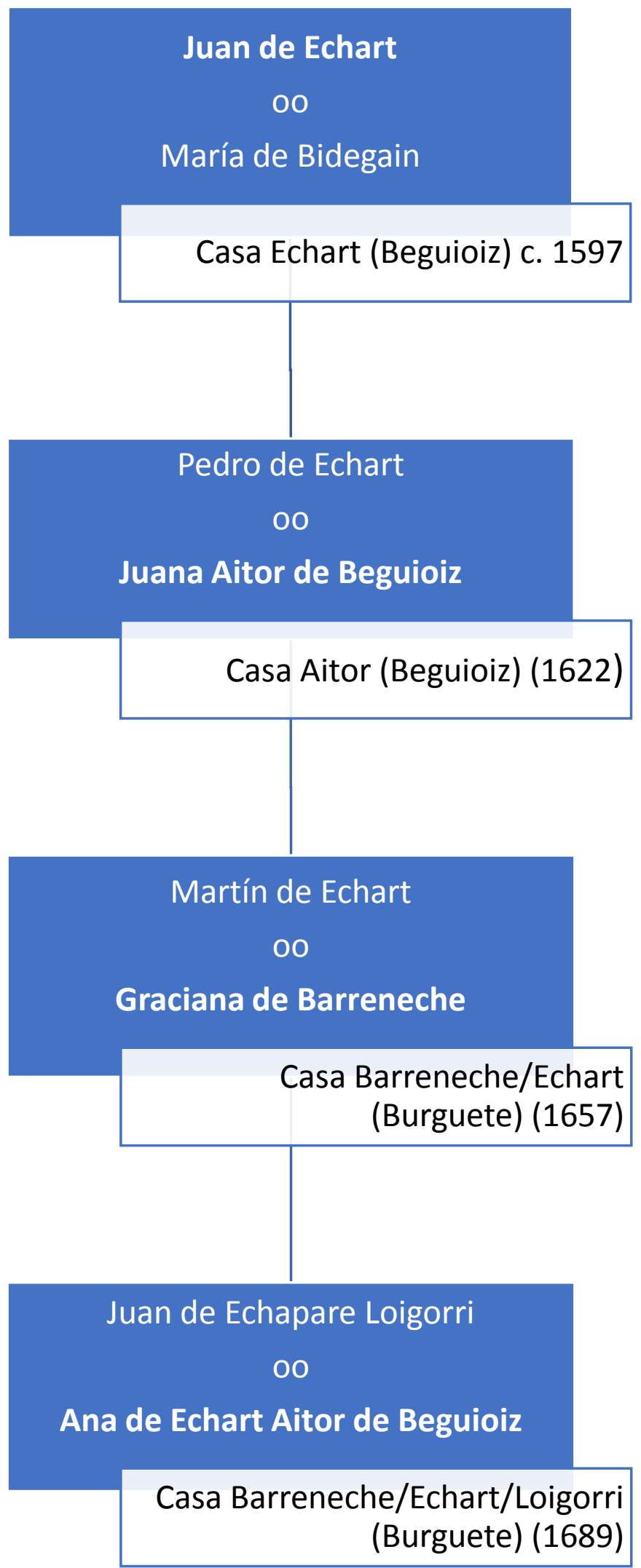

Gráfico 1. Descendientes de la casa Echart de Beguioiz (Baja Navarra). En negrita figura el heredero/a de la casa. 
Onomástica Desde América Latina, n. 2, v. 1, julho - dezembro, 2020, p. 17- 44. ISSN 2675-2719 https://doi.org/10.48075/odal.v1i2.25491

En torno a 1597 debió de contraer matrimonio el dueño de la casa de Echart del lugar de Beguioiz (Baja Navarra) ${ }^{10}$ su nombre era Juan de Echart: es decir, era conocido por el nombre de su solar de origen, del que era heredero. De su unión con María de Bidegain debieron de nacer varios hijos; el que aquí nos interesa, Pedro, era, según las fuentes, hijo menor, y no resultó elegido como heredero. En diciembre de 1622, por tanto, dos años después de la integración de Baja Navarra en la corona francesa, Pedro contrajo matrimonio con una mujer de su mismo pueblo que, como corresponde a la lógica del sistema, sí era heredera de su propia casa, de la que tomaba el nombre: Juana Aitor de Beguioiz, dueña de la casa de Aitor. De esta unión nacieron al menos tres hijos varones: uno de ellos heredó la casa; otro, llamado también Pedro, se ordenó sacerdote; por último, Martín de Echart se encontró en la misma situación que su padre veinticinco años antes: tras cobrar una dote, debía salir de su casa.

En 1657 Martín de Echart -súbdito del rey de Francia - cruzó los Pirineos rumbo al sur y contrajo matrimonio con una mujer heredera en la villa de Burguete, situada junto a la frontera, pero en la vertiente española. Su esposa, Graciana de Barreneche, era dueña de la casa de Barreneche de Burguete; al igual que sucede con sus vecinos del norte, también aquí el apellido se toma del solar. ${ }^{11}$ Sin embargo, a raíz de este matrimonio la casa de Barreneche empezó a ser conocida en Burguete como casa de Echart: en ello habría que ver tal vez razones como la fuerte personalidad del nuevo dueño, o quizá el empuje de su trabajo para mejorarla, o la temprana desaparición de su mujer: no es posible saberlo con la información que proporciona la fuente. Sin embargo, puede también pensarse que para esas fechas el proceso de "regularización" en las prácticas de uso y transmisión de nombres hubiera alcanzado a esta población: tal vez no a los protagonistas de esta historia, pero sí al escribano

\footnotetext{
${ }^{10}$ A pesar de las referencias que realizan algunos testigos a la condición noble de esta casa, no es seguro que lo fuera, al menos en la Baja Edad Media, como tampoco la de Aitor (ORPUSTAN, 2010: 274-275).

${ }^{11} \mathrm{Si}$ bien es prácticamente imposible precisar en cada caso concreto si el apellido se toma del solar o si ha sucedido a la inversa (DACOSTA, 2001: 93).
} 
Onomástica Desde América Latina, n. 2, v. 1, julho - dezembro, 2020, p. 17- 44. ISSN 2675-2719 https://doi.org/10.48075/odal.v1i2.25491

que dejó por escrito sus nombres; puede ser en efecto un rasgo de modernidad que el marido haya dado nombre a la casa propiedad de su mujer. El resultado, plasmado en el documento escrito, es que el oicónimo de raigambre local se abandonó en beneficio del foráneo que llegaba por vía masculina. Veintitrés años más tarde, Martín y Graciana eligieron como heredera de la casa a su hija Ana de Echart Aitor de Beguioiz, nacida en Burguete, quien repitió la historia de la generación precedente al contraer matrimonio en 1680 con un joven bajonavarro, llamado Juan de Echapare y Loigorri.

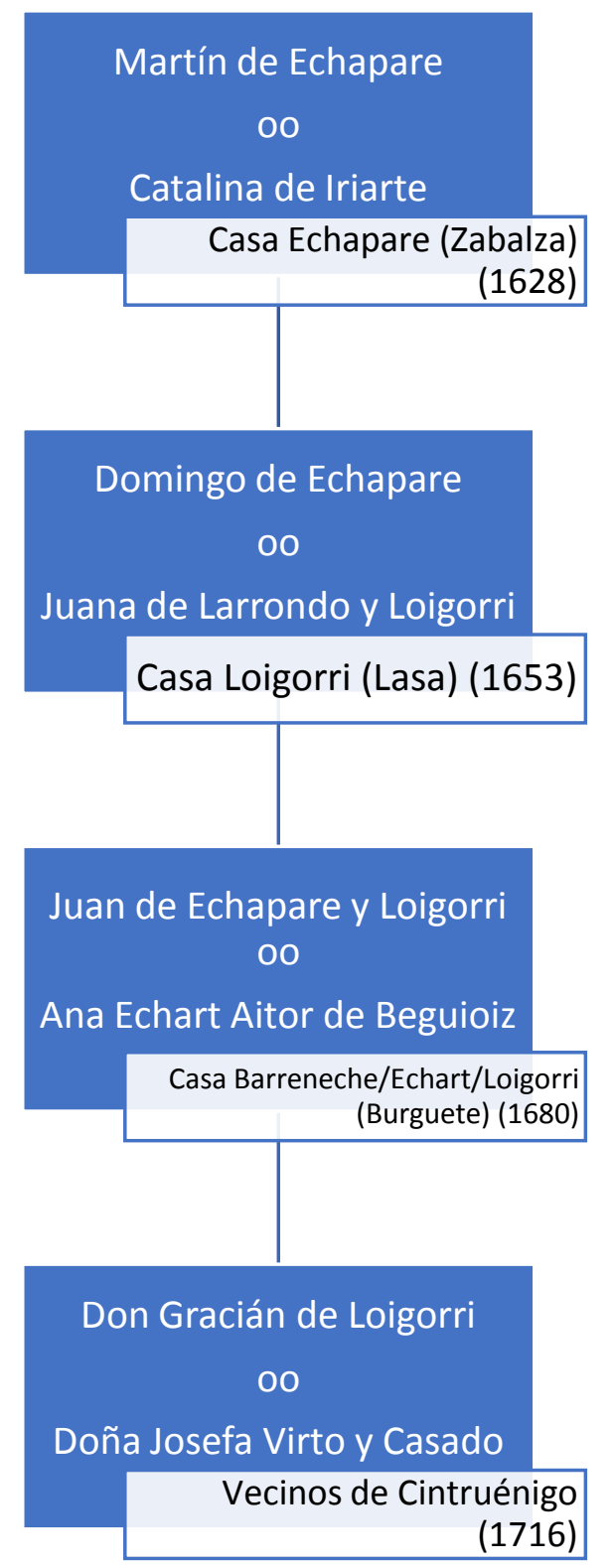

Gráfico 2. Descendientes de la casa Echapare de Zabalza (Baja Navarra). En negrita figura el heredero/a de la casa. 
Onomástica Desde América Latina, n. 2, v. 1, julho - dezembro, 2020, p. 17- 44. ISSN 2675-2719 https://doi.org/10.48075/odal.v1i2.25491

La familia Echapare ${ }^{12}$ presenta un recorrido similar a la de la casa de Echart, aunque los datos de la ejecutoria no permiten remontarse hasta finales del XVI, sino una generación posterior. Contemporáneo de Pedro de Echart, Martín de Echapare, dueño de la casa de Echapare en el lugar de Zabalza (Baja Navarra), ${ }^{13}$ junto a San Juan de Pie de Puerto, contrajo matrimonio en 1628 con Catalina de Iriarte: en este caso también el solar originario parece dar apellido al propietario. No es posible con la información de que dispongo saber qué hijo o hija de los Echapare-Iriarte recibió como herencia la casa en la siguiente generación, pero sí es seguro que no fue Domingo, coetáneo de Martín de Echart y abuelo del hidalgo de 1755. Domingo de Echapare casó en 1653 con Juana de Larrondo y Loigorri, dueña de la casa de Loigorri en el lugar de Lasa (Baja Navarra); ${ }^{14}$ es muy probable que Juana hubiera recibido la herencia de su propia madre, y tal vez por este motivo era conocida por los dos apellidos. En el caso de los Echapare la mudanza a la Alta Navarra se dio una generación más tarde que en el de Echart: un hijo desheredado de esta pareja, a quien se llama Juan de Echapare y Loigorri, cruzó la frontera para casarse, en 1680 y en Burguete, con la ya mencionada Ana de Echart, matrimonio en el que confluyeron las dos casas. Como se recordará, Ana había recibido el solar conocido primero como Barreneche y luego como Echart; ahora, durante este matrimonio, la casa experimentó un nuevo cambio de nombre pues pasó a ser conocida como Loigorri, que era muy probablemente el oicónimo de la suegra de Ana, y que ya entonces pudo ser el apellido por el que se conocía al esposo. Es decir, en dos generaciones sucesivas dos emigrantes bajonavarros dieron su nombre a una casa altonavarra; pero el segundo de ellos era un oicónimo transmitido en su lugar de origen por vía femenina.

Frente a estos ejemplos altonavarros en que parece detectarse una prevalencia de lo masculino, al menos en el documento escrito, en Baja Navarra la situación no parece haber

\footnotetext{
${ }^{12}$ La fuente oscila entre la forma Echapare y Echepare.

${ }^{13}$ Se trata de una antigua casa noble, documentada al menos desde 1340 (ORPUSTAN, 2010: 255).

${ }^{14}$ La casa de Loigorri no aparece documentada en Lasa en la Baja Edad Media, al menos con ese nombre
} (ORPUSTAN, 2010: 242-243). 
Onomástica Desde América Latina, n. 2, v. 1, julho - dezembro, 2020, p. 17- 44. ISSN 2675-2719 https://doi.org/10.48075/odal.v1i2.25491

evolucionado en ese sentido. A mediados del XVII seguía en vigor la costumbre de trasmitir el patrimonio a una hija, y no debía de resultar extraño que en tales casos el marido tomara el apellido de la casa de su esposa. Así lo explican algunos de los declarantes nada menos que un siglo después: Martín de Zaldumbide, dueño de la casa de Iturralde del lugar de Zabalza (Baja Navarra), de 96 años, afirma que “... es de usso en Navarra que los hixos varones que van en matrimonio, à otras cassas llevan, y se sirben del nombre de la casa donde se cassan, y que por lo comun no usan de otro que de este". ${ }^{15}$ Por su parte, Antonio, dueño propietario de la casa de Ancadoi, de San Juan el Viejo, maestro armero de 78 años, matiza: "que los hixos varones, sea de familia, sea de el comun, que se cassan con herederas, y van à las cassas de ellas, llevan, y se sirven de el nombre de la cassa, donde se cassan, y no ussan, sino de este, lo que es cierto y notorio en toda la vaxa navarra..."16 De lo anterior puede deducirse que, en el caso de los varones bajonavarros que abandonan su solar nativo con ocasión de matrimonio, el cambio de apellido se produce en el punto de llegada; y, en el caso de que la dueña de la casa sea la esposa, es el marido quien pasa a ser conocido por el oicónimo de aquella, mientras que la mujer no experimenta ningún cambio.

${ }_{16}^{15}$ Ejecutoria y certificación..., fo 346.

${ }^{16}$ Ejecutoria y certificación..., f ${ }^{\mathrm{o}} 356$. 
Onomástica Desde América Latina, n. 2, v. 1, julho - dezembro, 2020, p. 17- 44. ISSN 2675-2719 https://doi.org/10.48075/odal.v1i2.25491

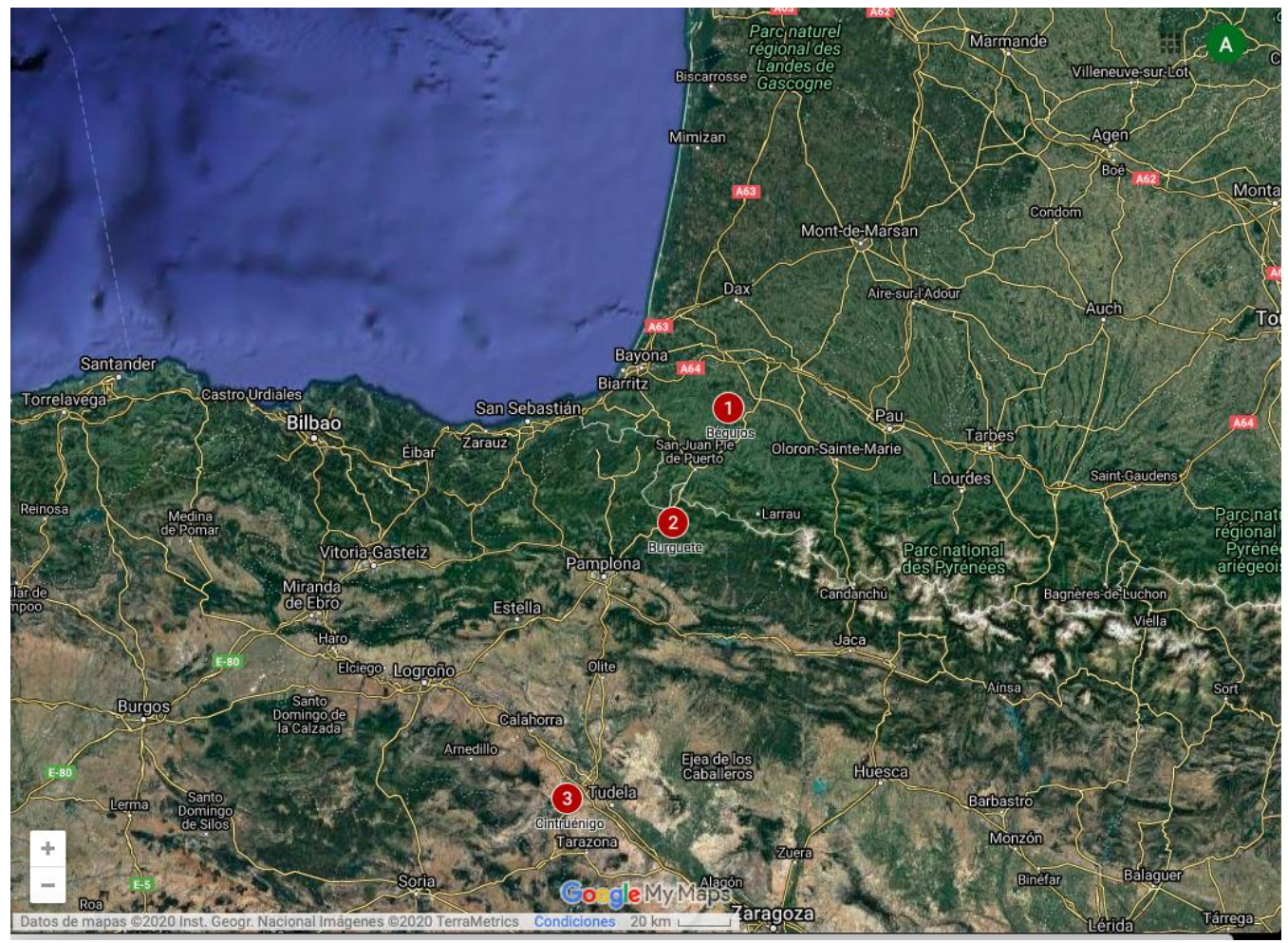

Mapa $n^{\circ}$ 2. El itinerario de la familia Echapare Loigorri: 1 Beguioiz (Baja Navarra). 2 Burguete (Alta Navarra). 3 Cintruénigo (Alta Navarra). Elaboración propia sobre Google Maps.

En 1690 los Echapare-Echart afincados en Burguete tuvieron un hijo, llamado Gracián, con el que las dos familias van a dar un paso más en la plena inserción en la Navarra peninsular. Gracián de Echapare desciende de dos palacios bajonavarros, pero en ambos casos de hijos segundones. Privado él mismo de la herencia a favor de algún hermano o hermana sus padres llevaban casados diez años cuando él nació-, debió buscar el modo de salir adelante. En 1716, con 21 años, va a emprender un viaje mucho más largo que el que realizara su padre, al recorrer los cerca de $140 \mathrm{~km}$ que separan su villa natal de la de Cintruénigo, en el valle del Ebro, situada en la frontera sur de Navarra, para casarse con doña Josefa de Virto y Casado, heredera de un notable patrimonio en esa localidad. ${ }^{17}$ Coincidiendo con su llegada a Cintruénigo, don Gracián dejó de utilizar el apellido Echapare para ser conocido simplemente con el de Loigorri, que como se ha visto era el de su bisabuela.

\footnotetext{
${ }^{17}$ Un testigo recuerda que en el viaje de ida y vuelta desde Baja Navarra se empleaban unos diez o doce días: Ejecutoria y certificación..., f f 355: declaración del testigo Antonio, dueño de la casa de Ancadoi, vecino del lugar de San Juan el Viejo.
} 
... Juan de Echapare, y Loigorri Padre de Don Gracian, usso en todo su tiempo de ambos apellidos, y por ello le corresponden a este sin embargo de que despues que passo a la rivera [del Ebro], solo ha ussado de el segundo, pues con ambas se le nombra en la partida de su Bauptismo, y es mui natural que el ussar solo de el de Loigorri, consista en que su abuelo Domingo, fue possehedor de la cassa de Loigorri en dicho lugar de Lassa, en el qual, y demas de su contorno, tiene comprehendido con notoriedad que ussan de el propio apellido, y el de la cassa, y veces solo de este, lo que tambien sucede en las montañas de este Reino [Alta Navarra], y en esta villa... ${ }^{18}$

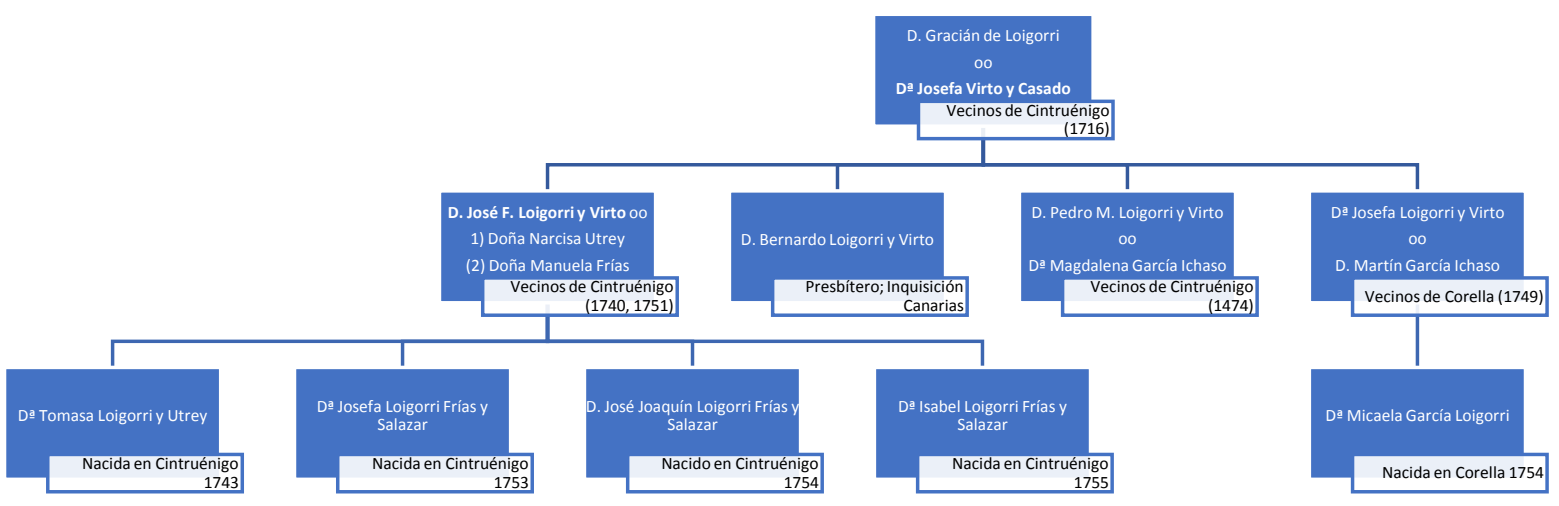

Gráfico 3. Descendientes de don Gracián de Loigorri. En negrita figura el heredero/a de la casa (en los casos en que se había designado).

En 1755, en plena madurez, con una numerosa familia, don Gracián de Loigorri y su esposa desearon hacer uso de los escudos de armas a fin de colocarlos en lugar visible en sus propiedades, para lo que emprendieron esta costosa investigación. Los Virto y sus ancestros apenas se habían movido del entorno en el que vivían durante varias generaciones, ${ }^{19}$ pero las pruebas a que debía someterse don Gracián implicaban un largo recorrido primero hasta Burguete, donde se había establecido su padre; averiguar la nobleza de los solares originarios conllevaba el examen de testigos vecinos de otro país, solicitando para ello la correspondiente autorización así como la traducción de las declaraciones una vez obtenidas, además de

18 Ejecutoria y certificación..., f $\mathrm{f}^{\mathrm{j}}$ 150: declaración del testigo Pedro de Azanza, vecino de Burguete. El subrayado es mío; lo que se afirma no es exacto, pues Domingo de Echapare se había casado con la dueña de la casa de Loigorri y solo por esta razón se le puede llamar possehedor de la misma. Es significativo el uso de este argumento, pues aplica retrospectivamente la visión que en aquel momento y lugar se tenía del papel del varón.

${ }^{19}$ No así la otra rama de la familia de doña Josefa, los Casado, pues eran oriundos del valle pirenaico altonavarro de Roncal: Ejecutoria y certificación..., fo $495-496$. 
Onomástica Desde América Latina, n. 2, v. 1, julho - dezembro, 2020, p. 17- 44. ISSN 2675-2719 https://doi.org/10.48075/odal.v1i2.25491

recorrer una distancia de más de $200 \mathrm{~km}$, superando la cordillera pirenaica. No cabe duda de que los Loigorri pusieron todo su empeño en lograr su objetivo.

Por lo que se refiere a los apellidos Echapare y Loigorri, la ejecutoria de 1755 ofrece la declaración de 36 testigos presentados por los Loigorri para probar su derecho; todos ellos son hombres, y viven en los lugares relacionados con la trayectoria que acabamos de resumir. Concretamente, 17 testigos declaran en Baja Navarra ( 9 en Amorots $^{20}$ y 8 en Zabalza, junto a San Juan de Pie de Puerto), y 19 en Alta Navarra (8 en Burguete y 11 en Cintruénigo y Corella, en la Ribera del Ebro). Al realizarse todas estas declaraciones en el plazo de pocos días, es posible analizar el grado de normalización onomástica en la información que se nos da de cada uno de estos testigos. Contamos además con un número similar de testimonios para cada una de esas localidades: las dos de Baja Navarra, la villa fronteriza de Burguete y las dos más pobladas en el sur, junto al Ebro.

\begin{tabular}{|c|c|c|c|c|c|}
\hline $\begin{array}{l}\text { LUGAR DE LA } \\
\text { DECLARACIÓN }\end{array}$ & $\begin{array}{c}\text { NÚMERO DE } \\
\text { TESTIGOS }\end{array}$ & $\begin{array}{c}\text { TESTIGOS QUE } \\
\text { FIRMAN }\end{array}$ & $\begin{array}{c}\text { TESTIGOS QUE } \\
\text { NO FIRMAN }\end{array}$ & $\begin{array}{c}\text { ORIGEN } \\
\text { BAJONAVARRO }\end{array}$ & $\begin{array}{c}\text { VARIANTES DE } \\
\text { APELLIDO }\end{array}$ \\
\hline $\begin{array}{c}\text { Amorots } \\
\text { (Baja } \\
\text { Navarra })\end{array}$ & 9 & 5 & 4 & & 2 carecen de él \\
\hline $\begin{array}{c}\text { Zabalza } \\
\text { (Baja } \\
\text { Navarra) }\end{array}$ & 8 & 0 & 8 & & 5 carecen de él \\
\hline $\begin{array}{c}\text { Burguete } \\
\text { (Alta } \\
\text { Navarra) }\end{array}$ & 8 & 5 & 3 & ¿3? & $\begin{array}{ll}\text { Sí } & \text { (una } \\
\text { oscilación) }\end{array}$ \\
\hline $\begin{array}{c}\text { Cintruénigo y } \\
\text { Corella } \\
\text { (Alta } \\
\text { Navarra) }\end{array}$ & 11 & 11 & 0 & 0 & Sí \\
\hline TOTAL & 36 & 21 & 15 & & \\
\hline
\end{tabular}

Tabla $n^{\circ}$ 1. Elaboración propia sobre datos de la Ejecutoria.

\footnotetext{
${ }^{20}$ Las declaraciones se realizaron en el palacio de este lugar, contiguo a Beguioiz, tal vez por no haber ningún espacio adecuado en la pequeña aldea de la que procedían los Echart. Asimismo, no todos los que declaran en Zabalza residen en este lugar, sino en sus alrededores.
} 
Un primer y valioso dato lo constituye la firma de cada declarante, al final de su testimonio. Las diferencias son acusadas: mientras 16 de los 19 testigos altonavarros estamparon su firma (el 84,21\%: en realidad el 89,47\% si tenemos en cuenta que uno de los testigos alegó no firmar por estar impedido), en cambio entre los bajonavarros solo lo hacen cinco $(29,41 \%) .{ }^{21}$ El contraste es abrumador si tomamos los ocho testigos que declaran en el lugar de Zabalza, pues ninguno de ellos sabía escribir. Casi el 90\% en las poblaciones integradas en la Monarquía Hispánica frente a menos del 30\% en suelo francés son sin duda datos relevantes.

Centrándonos en aspectos onomásticos, conviene atender a la fijación de la forma del nombre personal; esta cualidad puede deducirse gracias a que el nombre de cada testigo es citado al menos tres veces: una primera en la que se enumera a todos los declarantes de ese determinado lugar; otra segunda en el momento en que se le toma declaración; por último, en bastantes casos el nombre se menciona de nuevo al efectuarse la notificación al interesado. Llama la atención el hecho de que, tratándose del mismo día o como mucho la misma semana, en ocasiones el nombre aparece escrito con variantes. También en este aspecto se observan diferencias según lugares: mientras que en el territorio más castellanizado, el valle del Ebro, no se aprecia ninguna variante, en la villa pirenaica de Burguete se observa una ligera oscilación en el modo de llamar a uno de los sujetos. De nuevo, el contraste con la Navarra francesa es marcado: ${ }^{22}$ en Amorots no hay plena coincidencia en la escritura del nombre en

\footnotetext{
${ }^{21}$ Conviene señalar que las localidades de Alta Navarra implicadas en esta ejecutoria presentan un carácter urbano o semi-urbano, por contraste con las bajonavarras. En torno a 1786-1797, Lasa tenía 621 habitantes (GOYHENETCHE, 2001); Beguioiz y Zabalza no serían mayores. Burguete contaba con unos 319 (GARCÍASANZ y ZABALZA, 1983) y Cintruénigo, 1.736 (ALFARO, 2007), mientras que Corella tenía 3.693 (DOMÍNGUEZ y ALFARO, 2001). Junto a ello, debe tenerse en cuenta que cinco de los once declarantes de Cintruénigo y Corella eran sacerdotes, mientras que no hay ningún clérigo entre los bajonavarros.

${ }^{22}$ Las declaraciones tomadas en Baja Navarra corrieron a cargo de escribanos reales de ese territorio; pronunciadas en lengua vasca, fueron escritas en francés, como era preceptivo desde el edicto de VillersCotterêts (1539, aunque en este territorio se aplicaría al incorporarse a la corona francesa) (BRUNET, 2014: 74); una vez transferidas a la Alta Navarra, se tradujeron al castellano.
} 
Onomástica Desde América Latina, n. 2, v. 1, julho - dezembro, 2020, p. 17- 44. ISSN 2675-2719 https://doi.org/10.48075/odal.v1i2.25491

las diversas ocasiones en que aparece escrito; incluso en un par de casos de los ocho declarantes no se indica en ningún momento el apellido. También en este punto las declaraciones del lugar de Zabalza reflejan una situación arcaica: de cinco de los ocho testigos no se indica apellido, sino que son identificados por su nombre de pila y el nombre de su casa, como sucede por ejemplo con "Carlos, dueño propietario de la casa de Emategui" (individuo que, cuando es citado con ocasión de la notificación, aparece como "Carlos de Emategui", y previamente como "Carlos, dueño propietario de la casa de Mategui"), o "Guillome, dueño anciano y propietario de Yribarne". En realidad, el único declarante en esa localidad que aparece designado por un apellido es precisamente el único que carece de casa.

Sin perder de vista el papel fundamental desempeñado por los escribanos, que son quienes ponen por escrito, con la información de que disponen, los nombres de las personas, habría que deducir que, a mediados del XVIII, las poblaciones más castellanizadas de la Navarra peninsular presentan una onomástica más moderna, en la que el apellido es una pieza estable y transmitida de padre a hijo, lo que hace a un sujeto legible para el estado. Por el contrario, en el entorno rural de la Navarra francesa, más tardíamente incorporada a esa Monarquía, en una posición periférica agudizada por la disparidad lingüística, sin el elemento catalizador de las expediciones a Indias, han pervivido (al menos en la práctica notarial, pero ya es suficientemente indicativo) las formas tradicionales de denominación, estrechamente vinculadas al solar que proporciona el fundamento de la pertenencia a la comunidad. Particular interés reviste el contraste entre la situación en Burguete, villa próxima a la frontera, y las localidades situadas a muy pocos kilómetros, pero del otro lado del Pirineo, y que podría explicarse por una mayor presencia del estado al sur de la cordillera.

Pueden apuntarse brevemente otros tres aspectos que diferencian las dos Navarras a mediados del XVIII: la pervivencia de la costumbre de elegir como heredera a una mujer, la preservación de la memoria genealógica y la conservación de los libros parroquiales. 
Onomástica Desde América Latina, n. 2, v. 1, julho - dezembro, 2020, p. 17- 44. ISSN 2675-2719 https://doi.org/10.48075/odal.v1i2.25491

La persistencia de las viejas costumbres autóctonas relacionadas con la transmisión del bien más preciado, la casa, es notable en Zabalza: en los casos en que la fuente asigna nombre y apellido a un declarante, este último elemento no suele coincidir con el nombre de la casa de la que es dueño: "Martín de Zaldumbide, dueño propietario de la casa de Yturralde" (en la notificación aparece como "Martín de Yturralde"); "Domingo de Yturralde, dueño de la casa de Ynchauspe", lo que permite aventurar que habían accedido a esa unidad doméstica por matrimonio. En el caso de uno de los testigos que declararon en Amorots sabemos con certeza que era "advenedizo" a su casa; es decir, que la verdadera heredera fue su esposa. Se trata de Martín de Yssaguirre, dueño en 1755 de la casa de Aitor (Beguioiz) antes mencionada, quien recuerda en su testimonio que "antes de casarse con la heredera de la casa infanzona de Aitor, su mujer", la frecuentó durante tres años, según afirma para "hacer corte": es decir, para cortejar. Durante ese tiempo tuvo ocasión de hablar con el anciano abuelo de su novia, quien le contó que él mismo era hijo menor de la noble casa de Echart, en ese mismo lugar, y casó con Juana Aitor, heredera de la casa de Aitor. No muy diferente debía de ser la trayectoria vital de Gracián de Urruti, dueño de la casa de Mauhourat o Maulurat pero que había comenzado con unos 17 años como pastor de la citada casa de Echart. A mediados del XVIII, por tanto, en Baja Navarra no había desaparecido la costumbre de elegir como heredera del patrimonio a una mujer; esta tendencia se observaba por las mismas fechas en valles montañosos y apartados de la Navarra española, pero tendía claramente a desaparecer desde 1600 tanto en las villas como en los valles mejor comunicados (MORENO y ZABALZA, 1996: 274-287). Como señalara Braudel, las montañas son bastiones de arcaísmo (SCOTT, TEHRANIAN y MATHIAS, 2002: 14).

El contenido de las declaraciones de los testigos permite observar asimismo otras diferencias. A grandes rasgos, en los testimonios tomados en Cintruénigo y Corella se advierte un menor recurso a la memoria genealógica. Por contraste, los testimonios de 
Onomástica Desde América Latina, n. 2, v. 1, julho - dezembro, 2020, p. 17- 44. ISSN 2675-2719 https://doi.org/10.48075/odal.v1i2.25491

Burguete y Alta Navarra son muy ricos en lo que se refiere a la narración de la propia biografía, junto con una continua referencia a la memoria de los mayores. Este rasgo puede ponerse en relación con el carácter oral de la cultura vasca, transmitida al margen de lo escrito.

Es indudable que los oficiales de la Monarquía contribuyeron a la atribución y fijación de los nombres; pero no se puede olvidar que la Iglesia católica comenzó a llevar registro de sus fieles trescientos años antes que el estado. Aunque los libros parroquiales difícilmente pudieron fijar las formas o normalizar la transmisión de apellidos, tampoco puede obviarse su existencia. De hecho, en el curso de procesos judiciales o investigaciones para la obtención de ejecutorias, como la aquí analizada, se recurrió a ellos con fin probatorio. En este sentido, las dos Navarras experimentaron vivencias dispares, pues la parte española no conoció la fractura religiosa. Una consecuencia es que los libros parroquiales se llevaron y conservaron desde fechas tempranas en Alta Navarra, pero no siempre en la Navarra francesa. Al recabar pruebas en apoyo a la solicitud de Echapare, en el lugar de Beguioiz

se ha presentado el señor Don Pedro de Lespade, sacerdote, Doctor en Theologia, y cura de el presente lugar, quien declaró que el fue provisto de este veneficio hace veinte y dos años [en 1733], y que no encontró en su iglesia ni en poder de los herederos de el señor de Arriet cura su predecesor ia difunto las partidas de Baptismos y matrimonios de el presente lugar [...] y que desde entonces no ha podido descubrirlas en ninguna parte. ${ }^{23}$

\section{Conclusiones}

De las declaraciones de los testigos puede deducirse que el proceso de fijación de apellidos y en definitiva de modernización onomástica, concediendo papel preponderante a la aportación masculina, parece en 1755 más avanzado en la Navarra española que en la francesa. En las localidades de Baja Navarra el apellido y el lugar de vecindad desempeñan un papel secundario en la identificación de las personas frente al peso de la casa: en el caso del

\footnotetext{
${ }^{23}$ Ejecutoria y certificación..., f $\mathrm{f}^{\mathrm{j}}$ 390-391. En cambio, sí se conservaron en San Juan el Viejo, donde se impuso la Reforma (OLAIZOLA, 1993: 127) y en Lasa. Por contraste, en la iglesia de San Juan Bautista de Cintruénigo los libros más antiguos comienzan en 1565: es decir, muy poco después de la finalización del Concilio de Trento (Ejecutoria y certificación..., fo 497).
} 
Onomástica Desde América Latina, n. 2, v. 1, julho - dezembro, 2020, p. 17- 44. ISSN 2675-2719 https://doi.org/10.48075/odal.v1i2.25491

heredero, el oicónimo no varía a lo largo de la vida, pero en el de sus hermanos sí, aunque no de manera regular sino en función de una casuística inabarcable. En cambio, en el valle del Ebro el apellido y la vecindad resultaban determinantes, con la consiguiente estabilidad en el uso y transmisión de apellidos; la referencia a la casa aparece cuando se trata de probar determinados derechos, especialmente en los abundantes casos en que el linaje procedía de los valles septentrionales.

Algunos de los factores que dificultaban la legibilidad seguían presentes en Baja Navarra a mediados del XVIII: el apellido no constituía una pieza estable, recibida del padre, vaciada de significado. Al menos en algunos de los casos que se ha examinado hemos podido comprobar cómo la mujer heredera de patrimonio transmite su propio oicónimo a sus hijos e incluso a su marido, pero a su vez aquellos lo perderán cuando abandonen el hogar nativo. No faltan ejemplos, como el de Loigorri, en el que un oicónimo antiguo se sitúa por delante de los apellidos de ambos cónyuges. Circunstancias particulares que escapan a los estrechos márgenes impuestos por los documentos escritos podían subrayar uno de estos nombres y dejar caer en el olvido otros, de una manera perfectamente lógica en el escenario local pero opaca e inasumible para el estado. En cambio, en el valle del Ebro, junto a la frontera tanto con Castilla como con Aragón, donde durante siglos se situaron las aduanas fiscales y circularon personas, mercancías y dinero, el proceso de regularización se encontraba mucho más avanzado, también en familias que, como la aquí estudiada, procedían de regiones que conservaban vivas las prácticas tradicionales. Entre uno y otro extremo se situaría la villa fronteriza altonavarra de Burguete, en la que la Ejecutoria permite deducir una coexistencia de la costumbre popular con la pauta moderna.

Debe no obstante añadirse que las formas oficiales, impulsadas desde el estado, no suponen la desaparición de las formas tradicionales, que identifican a un individuo y lo clasifican dentro de su grupo doméstico: unas y otras coexisten, y cada una es eficaz en el 
Onomástica Desde América Latina, n. 2, v. 1, julho - dezembro, 2020, p. 17- 44. ISSN 2675-2719 https://doi.org/10.48075/odal.v1i2.25491

ámbito que le es propio (SCOTT, TEHRANIAN y MATHIAS, 2002: 31-32). Esta coexistencia no se da entre dos sistemas paralelos: una especie de traducción de palabras; las denominaciones vernáculas europeas, y aquí tenemos un buen ejemplo, presentaban, frente a los intentos homogeneizadores del estado, rasgos que debían ser corregidos de acuerdo con las nuevas pautas, pero plenos de significado para los miembros de estas comunidades. Algunos de estos rasgos eran el hecho de que un individuo cambiara de nombre a lo largo de su curso vital, incluso siendo conocido simultáneamente por varios nombres en diferentes ámbitos, y la ausencia de marcadores de filiación. Estos factores no impedían la legibilidad de un individuo en la escala local en cada etapa de su curso vital ni su clasificación dentro del grupo doméstico, pero eran incompatibles con los objetivos que se proponía el estado. La mejor prueba de que otros nombres existían y se usaban la constituye el hecho de que todavía hoy en el ámbito rural la identificación se realiza por vías informales. ${ }^{24}$

Tras su establecimiento en la comarca más próspera de la Navarra peninsular, don Gracián de Loigorri adoptó una serie de decisiones que marcaban distancias respecto de sus antepasados. Por su rama paterna, tanto su abuelo como su padre — y él mismo — habían sido desheredados y se habían casado con mujeres con patrimonio. Por la rama materna esta misma situación se prolongaba incluso una generación más, hasta su bisabuelo. En cambio, don Gracián y su esposa transmitieron su patrimonio al primogénito de sus hijos, a quien impusieron nombres que rompían con la tradición familiar al menos paterna, pues se llamó José Francisco Fermín. Casado a los veintitrés años con una mujer de su misma villa, pronto quedó viudo y contrajo un segundo matrimonio con una castellana, doña Manuela Frías y Salazar. Un segundo hijo, Bernardo, estudió Leyes, se ordenó sacerdote y, al servicio de la Inquisición, se estableció en las islas Canarias. El hijo y la hija menores se casaron con dos

\footnotetext{
${ }^{24}$ En pleno siglo XXI varias localidades de la actual Comunidad Foral de Navarra han editado sus propios directorios telefónicos, que no son listas de abonados sino de casas, pues el oicónimo sigue siendo el elemento que permite identificar a las personas.
} 
Onomástica Desde América Latina, n. 2, v. 1, julho - dezembro, 2020, p. 17- 44. ISSN 2675-2719 https://doi.org/10.48075/odal.v1i2.25491

hermanos de la vecina ciudad de Corella, apellidados García Ichaso. En seis generaciones la huella bajonavarra prácticamente había desaparecido.

Recebido em11/05/2020

Aceito em 24/06/2020

Publicado em 29/07/2020

\section{Bibliografía}

Alfaro Pérez, F. J. (2007). Historia de la villa de Cintruénigo. Cintruénigo: Ayuntamiento de Cintruénigo.

Brunet, S. (2017). Los Pirineos en el siglo XVI: una frontera religiosa. En F. Ciaramitaro y J. de la Puente Brunke (coords.) Extranjeros, naturales y fronteras en la América ibérica y Europa (1492-1830) (pp. 115-180). México: Universidad Autónoma de la Ciudad de México; Universidad de Murcia.

Brunet, S. (2014). Perceptions identitaires et nationales dans la France de la première modernité: de la francité et de l'hispanité des gascons. En M.-V. Dimitriev y D. Tollet (eds.) Confessiones et nationes. Discours identitaires nationaux dans les cultures chrétiennes, Moyen Âge-XXe siècle (pp. 57-125). París: Honoré Champion.

Chacón, F. y Bestard, J. (dirs.) (2011). Familias: historia de la sociedad española (del final de la Edad Media a nuestros días). Madrid: Cátedra.

Dacosta, A. (2001). Estructura, uso y funciones del nombre en la Baja Edad Media: el ejemplo de los hidalgos vizcaínos. Vasconia, 31, 91-112.

Domínguez Cavero, B. y Alfaro Pérez, F. J. (2001). La ciudad de la hidalguía. Corella (Navarra) ss. XVI-XVIII (1). Familias y emblema. Emblemata, 7, 233-287.

Floristán, A. (2014). El Reino de Navarra y la conformación política de España (1512-1841). Madrid: Akal. 
Onomástica Desde América Latina, n. 2, v. 1, julho - dezembro, 2020, p. 17- 44. ISSN 2675-2719 https://doi.org/10.48075/odal.v1i2.25491

Floristán, A. (2007). Adaptaciones divergentes: Las Cortes de Navarra y los "États de Navarre" (siglos XV-XVIII). Anuario de historia del derecho español, 77, 177-253.

Floristán, A. (2006). Reino de Navarra en España y Royaume de Navarre en Francia: evoluciones diferentes (1512-1789/1839). En M. Galán, M. M. Larraza y L. E. Oslé, Navarra: memoria e imagen (Vol. 3, pp. 121-154). Pamplona: Eunate.

García-Sanz Marcotegui, Á. y. Zabalza Cruchaga, M. Á. (1983). Consecuencias demográficas de la Guerra de la Convención en Navarra. La crisis de mortalidad de 1794-1795. Príncipe de Viana, 168, 63-87.

Goñi Gaztambide, J. (1985). Historia de los obispos de Pamplona. Siglo XVI (Vol. IV). Pamplona: Eunsa-Gobierno de Navarra.

Goyhenetche, M. (2001). Histoire Générale du Pays Basque. Évolution économique et sociale du XVIe au XVIIIe siècle (Vol. III). Donostia: Elkarlanean.

Herreros Lopetegui, S. (1996). La "Tierra de Vascos". Irredentismos de doble dirección. En Á. J. Martín Duque. Signos de identidad histórica para Navarra (Vol. II, pp. 221-234). Pamplona: Caja de Ahorros de Navarra.

Monteano Sorbet, P. J. (2017). El iceberg navarro. Euskera y castellano en la Navarra del siglo XVI, Pamplona: Pamiela.

Monteano Sorbet, P. J. (2015). La carta bilingüe de Matxin de Zalba (1416). El iceberg lingüístico navarro. Fontes Linguae Vasconum, 119, 147-173.

Moreno Almárcegui, A. y Zabalza Seguín, A. (1996). Fraternidad y género en un sistema de heredero único. En D. Comas d'Argemir (coord.) Familia, herencia y derecho consuetudinario (pp. 41-64). Huesca: Instituto Aragonés de Antropología.

Olaizola, J. M. (1993). Historia del Protestantismo en el País Vasco. El reino de Navarra en la encrucijada de su historia. Pamplona: Pamiela. 
Orpustan, J.-B. (2010). Les noms des maisons médiévales en Labourd, Basse-Navarre et Soule. (R. d. URL) Bordeaux.

Riezu, J. de (1985). Limpieza de sangre del caballero D. Pedro de Ursua y Arizmendi. Aingueru Irigarayri Omenaldia. Cuadernos de Sección Hikuntza eta Literatura, 4, 531534.

Rogers, S. C. (1979). Espace masculin, espace féminin. Essai sur la différence. Études rurales, $74,87-110$.

Salas Auséns, J. A. (2009). En busca de El Dorado. Inmigración francesa en la España de la Edad Moderna. Bilbao: Universidad del País Vasco.

Scott, J. C.; Tehranian, J. y Mathias, J. (2002). The Production of Legal Identities Proper to States: The Case of the Permanent Family Surname. Comparative Studies in Society and History, 44, 1, 4-44.

Vázquez de Prada, V. (1993). Las Cortes de Navarra desde su incorporación a la corona de Castilla. Tres siglos de actividad legislativa (1513-1829) (Vol. I). Pamplona: Eunsa.

Yaben, H. (1916). Los contratos matrimoniales en Navarra y su influencia en la estabilidad de la familia. Pamplona: Jaime Ratés.

Zabalza Seguín, A. (2018). "Por no pertenecerles el apellido". La formación de los apellidos en la Navarra Moderna. En A. Zabalza Seguín. De Engracia a Garazi. El misterio de los nombres en Navarra (pp. 109-148). Cizur Menor: Thomson Reuters Aranzadi. 